Article

\title{
Why Do Medium-Sized Technology Farms Adopt Environmental Innovation? The Mediating Role of Pro-Environmental Behaviors
}

\author{
Stanley Y. B. Huang ${ }^{1}\left(\mathbb{D}\right.$, Ming-Way Li $^{2, *}$ and Yue-Shi Lee ${ }^{3} \mathbb{D}$ \\ 1 Master Program of Financial Technology, School of Financial Technology, Ming Chuan University, \\ Taipei 111, Taiwan; yanbin@mail.mcu.edu.tw \\ 2 Department of Marketing and Logistics Management, College of Business Management, \\ Chihlee University of Technology, New Taipei 220, Taiwan \\ 3 Department of Computer Science and Information Engineering, Ming Chuan University, \\ Taoyuan City 333, Taiwan; leeys@mail.mcu.edu.tw \\ * Correspondence: vincent@gm.chihlee.edu.tw
}

Citation: Huang, S.Y.B.; Li, M.-W.; Lee, Y.-S. Why Do Medium-Sized Technology Farms Adopt Environmental Innovation? The Mediating Role of Pro-Environmental Behaviors. Horticulturae 2021, 7, 318. https://doi.org/10.3390/

horticulturae7090318

Academic Editor: Christian Fischer

Received: 5 August 2021

Accepted: 15 September 2021

Published: 16 September 2021

Publisher's Note: MDPI stays neutral with regard to jurisdictional claims in published maps and institutional affiliations.

Copyright: (c) 2021 by the authors. Licensee MDPI, Basel, Switzerland. This article is an open access article distributed under the terms and conditions of the Creative Commons Attribution (CC BY) license (https:/ / creativecommons.org/licenses/by/ $4.0 /)$.

\begin{abstract}
This research fills several gaps in the literature not investigated in previous studies. First, it examines how the responsible leadership (RL) of the chief executive officer (CEO) influences mediumsized technology farms to adopt environmental innovation (EI) through the pro-environmental behaviors (PBs) of the senior executive team (SET) according to the theory of social learning, as previous research only took institutional theory and utilitarianism as the driving factors of agricultural innovation. Second, we propose the potential growth model (PGM) from a sample of 105 CEOs and their SETs in medium-sized technology farms to handle the problem that an individual may regulate his behaviors based on how he translates and understands the surrounding environment, because previous research has ignored this perspective. Lastly, this research offers recommendations for the implementation of EI in medium-sized technology farms and also expands the related literature on sustainable agricultural production.
\end{abstract}

Keywords: responsible leadership; environmental innovation; medium-sized farms; pro-environmental behaviors

\section{Introduction}

Contemporary medium-sized technology farms are having to deal with a wide array of environmental issues that are a significant source of sustainable production [1-3], which comes from the pressure of external stakeholders [4-6]. Indeed, external pressures from governments, media, and consumers have also encouraged farm enterprises to adopt new methods to achieve sustainable consumption and production strategies for the environment [7-9] because agricultural production has caused great pollution [10-13]. Therefore, exploring the key variables for environmental innovation (EI) in medium-sized technology farms is crucial, because EI can improve their performance and environmental sustainability [14-16]. EI refers to the improvement of business and production activities by enterprises through environmental innovation [17,18], and in Taiwan's agriculture sector, it is a significant issue [19-21]. Previous researchers have also shown the significance of exploring EI and its antecedents [22-24].

The literature covering the driving factors of agricultural innovation adoption in the past has not fully studied this topic, because researchers almost always use the institutional theory [25] or information technology adoption models to predict innovation adoption [26-28]. To supplement the driving factors of EI in the agricultural sector and provide important incremental contributions, this present research uses the theory of social learning [29] to construct an EI adoption model that integrates the responsible leadership (RL) of the chief executive officer (CEO) and the pro-environmental behaviors (PBs) of 
the senior executive team (SET). The goal is to see how the growth of pro-environmental behaviors (PBs) of SET might predict the growth of EI adoption. We define RL as the degree of leadership behaviors that pay attention to the interests of various stakeholders, such as economic, social, and environmental benefits [30,31]. PBs are the degree of an individual's voluntary behavior toward improving the environment [32]. The theory of social learning [29] believes that people may adjust their behavior through imitating other people. As a corporate leader may make his subordinates imitate his RL's environmental behaviors, the PBs of these subordinates should experience an increase, thereby indicating a clear relationship between RL and PBs.

As discussed above, the significant incremental contribution of this paper is to present the driving factors for the adoption of EI from the CEO-SET nexus, because past researchers have not checked such links in medium-sized technology farms. The present research proposes the term growth of PBs and EI because it denotes an important gap in behavioral science research. In other words, past behavioral science research has almost exclusively applied cross-sectional designs to test innovations in the agricultural field [33,34]. Thus, it is speculated that people will adjust their behavioral intention level by how they understand and translate their behavioral intentions according to their current environment, which has not been fully reviewed. This study collected a sample of 105 CEOs and their SETs from medium-sized technology farms in Taiwan over a six-month period to analyze the adoption model versus the potential growth model (PGM) [35].

\subsection{RL of CEOs and EI Adoption}

$\mathrm{RL}$ is the ability of the leadership to maintain relationships with stakeholders through the four mechanisms of understanding, acquisition, protection, and connection [36]. The theory of social learning [29] puts forward that the subordinate (e.g., SET) can imitate the attitudes of the responsible leader (e.g., CEO) on environmental issues through the interaction process of RL, and so SETs should prefer EI due to the RL process. Indeed, previous studies have also suggested that a leader has the responsibility to improve environmental problems and EI [37-39], and so EI may be one of the solutions. We now present the first hypothesis.

Hypothesis 1. Higher levels of RL of CEOs at time point 1 influence more positive changes in the adoption of EI.

\subsection{RL of CEOs and PBs of SETs}

The theory of social learning [29] supports the relationship between RL and PBs because subordinates can imitate the attitudes of their responsible leaders on environmental issues through the interaction process of RL, thus forming a similar concept of PBs. Indeed, a previous study [40] proposed that a leader can guide subordinates to satisfy the leader's preferences or values through leadership actions, and the preference or value of a responsible leader should relate to voluntary behaviors in dealing with environmental issues. This is similar to the definition of PBs. Moreover, a previous study proposed that RL may lead to PBs [41], thus helping to form the next hypothesis.

Hypothesis 2. Higher levels of RL of CEOs at time point 1 influence more positive changes in PBS of SETS.

According to the theory of social learning [29], employees of these medium-sized technology farms examined herein should similarly imitate the attitudes of their supervisor on environmental issues, and so employees throughout the company that should prefer EI. Indeed, previous researchers have pointed out that employees with high levels of PBs will actively initiate innovation because intrinsic motivation can drive these employees to incorporate environmental standards into their work processes [42]. We hence offer the next hypothesis. 
Hypothesis 3. More positive changes in PBS of SETs influence more positive changes in a company's EI adoption.

\section{Results}

\subsection{Sample}

We collected samples of CEOs and SETs of medium-sized technology farms in Taiwan for PGM analysis over three separate time periods with an interval of three months. Each time period is separated by three months to satisfy PGM statistical analysis [43-45].

Because the innovation strategy of medium-sized technology farms in this country has gradually attracted attention [46], this research queried several domestic agricultural associations. These medium-sized technology farms adopt the new technique to produce agricultural-related products and horticultural-related products. For example, these farms use light-emitting diode lighting systems to grow flowers or use aquaponics technology to grow vegetables. We contacted these technology farms by telephone and invited their CEOs and SETs to join the study, with 106 CEOs and their SETS eventually taking part. We gathered the questionnaires of CEOs and SETs through e-mail to prevent CEOs from obtaining information about SETs, because deviations in social expectations may arise. We also notified these CEOs and SETs in advance that their raw data will not be provided to anyone. These medium-sized technology farms are all corporate enterprises, with a formal organizational system, good employee benefits, and a capital scale of more than US $\$ 50,000$.

At time point 1, we collected the PBs evaluation of SETs by these CEOs and the RL of CEOs and EI evaluation by SETs. The sample at this first time point was 105. At time point 2, three months later, the PBs evaluation of SETs by these CEOs and the EI evaluation by SETs were collected again. At time point 3, six months later after the start, we collected the evaluations of these CEOs and SETs for the last time. The sample design of three-time points was used because this research aimed to capture repeated measurements through PBs and EI to verify the hypothesis. Finally, common method deviation was handled by labeled variables [47]. Moreover, the sample design of multiple times (three time points) and multiple sources (CEOs and SETs) can also alleviate common method deviation [48].

\subsection{Measure}

We used reverse translation to confirm the quality of translation and a Likert sevenpoint self-report questionnaire to measure RL, EI, and EI. For example, if a CEO believes that his company does not adopt EI at all, then the CEO will choose an answer that strongly disagrees in the EI description item, which is coded with 1 point. If the SET members strongly agree with the description of their team's PBs, then they will check the PBS description to choose an answer that strongly agrees, which is coded by 7 points. Based on the encoded numerical scores, we then performed statistical analysis to verify the hypothesis.

We evaluated RL based on the scale of Voegtlin et al. [31]. PBs were evaluated from the scale of Boiral and Paillé [49]. Finally, the Song and Yu [18] scale was employed to measure EI.

\subsection{Analysis}

This survey borrowed from factor analysis (FA) and different chi-squared tests to analyze validity and reliability. We show the results of FA in Tables 1 and 2, which are in line with the suggestion of past research [50].

We used the potential growth model to analyze the path relationships between RL of CEOs, PBs of SETs, and EI adoption (please see Figure 1). First, CEOs' RL at phase 1 has a positive effect on the changes in EI adoption $(\beta=0.25, p$-value $<0.01)$, thus verifying Hypothesis 1 . In other words, RL in phase 1 can increase the company's EI adoption over time. Second, CEOs' RL in phase 1 time positively affects changes in PBs of SETs ( $\beta=0.34$, $p$-value $<0.01$ ), thus verifying Hypothesis 2 . In other words, RL in phase 1 can increase the PBs of SETs over time. Finally, more positive changes in the PBs of SETs can lead to more 
positive changes in the company's EI adoption $(\beta=0.32, p$-value $<0.01)$, thus verifying Hypothesis 3. In other words, more changes in the PBs of SETs can result in positive changes in the adoption of EI.

Table 1. CFA Results.

\begin{tabular}{cccc}
\hline Component & Eigenvalue & \% of Variance & Cumulative \% \\
\hline Responsible Leadership & 2.2 & $26 \%$ & $26 \%$ \\
Pro-Environmental Behaviors & 2.1 & $24.8 \%$ & $50.8 \%$ \\
Environmental Innovation & 1.3 & $15.3 \%$ & $66.1 \%$ \\
\hline
\end{tabular}

Table 2. Reliability and Validity.

\begin{tabular}{ccc}
\hline Construct & Composite Reliability & Average Variance Extracted \\
\hline Responsible Leadership & 0.77 & 0.68 \\
Pro-Environmental Behaviors & 0.79 & 0.69 \\
Environmental Innovation & 0.80 & 0.71 \\
\hline
\end{tabular}

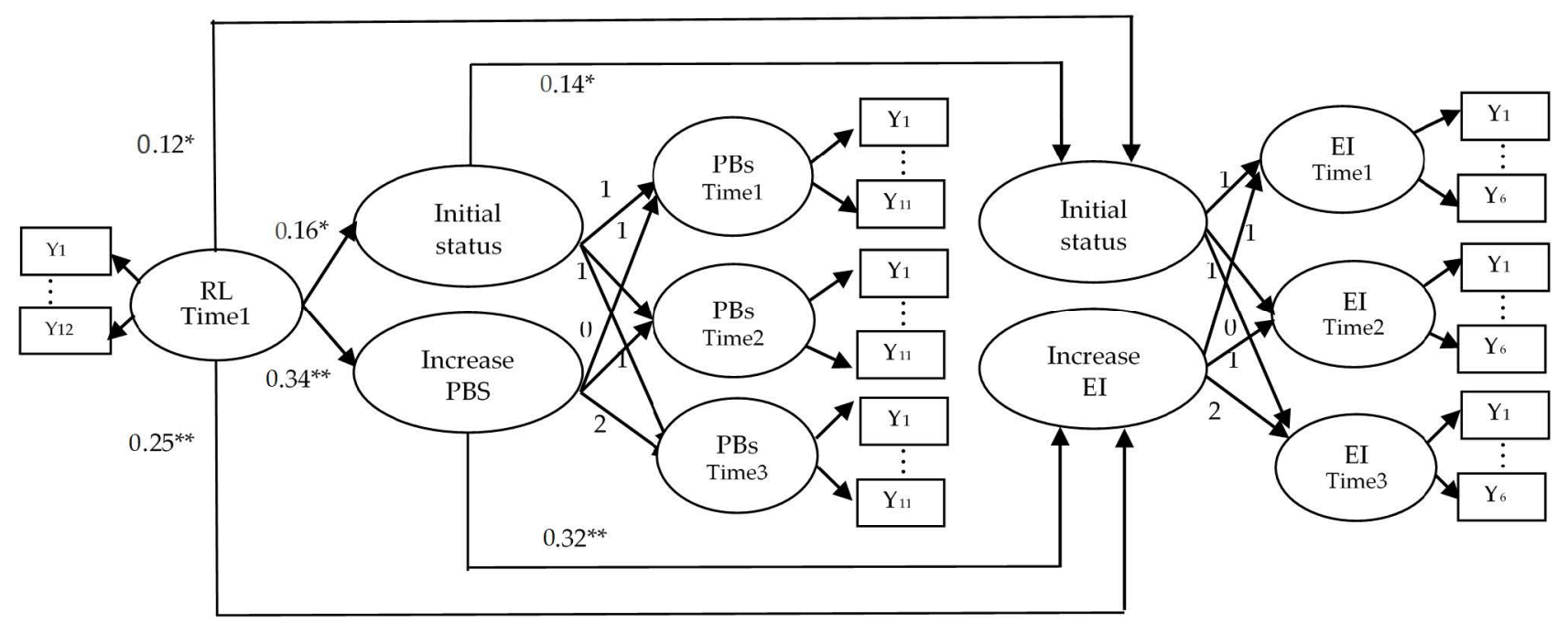

Figure 1. The PGM of the present survey. $\mathrm{RL}=$ Responsible Leadership; PBs = Pro-Environmental Behaviors; $\mathrm{EI}=$ Environmental Innovation. ${ }^{*} p<0.05 ;{ }^{* *} p<0.01$.

\section{Discussion}

\subsection{Academic Contribution}

First, this study took the mediating role of PBs based on the social learning theory and used PGM to verify the connection between RL and EI, thereby filling the gaps in the literature. According to the proposed model, the RL of CEOs at phase 1 can predict the changes in PBs of SETs, and the changes in PBs of SETs can also predict the changes in the company's EI adoption, hence proving high levels of validity for the proposed model in this research. Put differently, this survey used PGM for the first time and sampled 105 CEOs and SETs from medium-sized technology farms to demonstrate the psychological mechanism of CEO's and SET's influence on a company's strategic choices.

Second, past research on innovation has mainly focused on investigating which driving variables result in the employee's innovation in the R\&D department of technology companies [51-53]. Therefore, exploring what factors can push the environmental innovation of these medium-sized farms can help them to not only significantly reduce pollution and resource consumption but also achieve the goal of sustainable production. 
Third, the model proposed herein was tested with samples linked by CEOs-SETs, and PGM verified the model's causality. The results show that the CEO's RL is beneficial to EI adoption. This research not only proposes a new mechanism to drive innovation in the agricultural field, but also responds to previous research calls for exploring the relationship between leadership and green innovation [54,55], which has a significant incremental contribution to the literature of RL, PBs, and EI in this field.

Finally, this study also proposes that SETs with high levels of PBs can convert the CEO's RL into EI, thus confirming the importance of SET for the agricultural industry. Indeed, one study has suggested that SETs have the function of influencing the formulation of their company's strategy, but the formulation process is a so-called black box [56]. The theoretical model of this study illustrates the process of formulating a green innovation strategy, offering another incremental contribution to the SET literature.

\subsection{Practical Contribution}

First, the present study puts forward a specific management mechanism adopted by medium-sized farms to implement EI. To achieve the goal of sustainable production, vendors of medium-sized farms who intend to adopt EI should confirm the CEO's RL and SET's PBs of those farms, because RL and EI are crucial factors that promote a company's adoption of EI. EI is also a crucial strategy because EI can not only meet the expectations of stakeholders (e.g., government, media, and consumer) but also increase sustainable production.

Second, the model proposed in our study also points out that the CEO should not only implement RL to guide SET but also help SET know the importance of environmental sustainability because it can increase the possibility of SET participating in PBs. For example, the CEO can assign environment-related tasks to the SET, which would allow them to experience the importance of environmental sustainability.

Finally, the present study also exhibits the importance of RL, because it facilitates the adoption of EI. Therefore, it is worthwhile investing resources in RL education and training, because it can help senior supervisors improve their RL skills.

\subsection{Further Research and Limitations}

First, although this study uses PGM to analyze the causal relationship between EL, PBs, and EI adoption, more samples and a long time can be employed to confirm the stability. For example, future research can adopt more samples and a longer-term experimental design to increase stability. Second, the driving factors for EI adoption are not just the CEO's RL and SET's PBs; further research should explore more driving variables of EI in other contexts. Finally, past research has suggested that specific samples can test theories [57], but because the 105 samples in this survey are from medium-sized technology farms in Taiwan, further research should check our proposed model in different countries to verify its generalization.

\section{Conclusions}

This research investigated the reasons for adopting EI in Taiwan's medium-sized technology farms. Indeed, the EI is an important source of sustainable production in the agricultural sector, so this research adopted RL as the driving factor for the adoption of EI through the intermediary mechanism of the SET's PBs. The survey results showed that the CEO's RL at the phase 1 point can affect the positive changes in the SET's PBs, which in turn affects the positive changes in the adoption of EI by medium-sized farms over time. This research is the first to construct the milestone that poses the novel EI adoption model and employs the PGM to empirically examine the model proposed in the present survey.

Author Contributions: Conceptualization, S.Y.B.H.; methodology, M.-W.L.; software, M.-W.L.; validation, S.Y.B.H.; formal analysis, M.-W.L.; investigation, M.-W.L.; resources, Y.-S.L.; data curation, Y.-S.L.; writing-original draft preparation, S.Y.B.H.; writing—review and editing, S.Y.B.H.; visualization, M.-W.L.; supervision, S.Y.B.H.; project administration, S.Y.B.H.; funding acquisition, Y.-S.L. All authors have read and agreed to the published version of the manuscript. 
Funding: This research received no external funding.

Institutional Review Board Statement: Not applicable.

Informed Consent Statement: Not applicable.

Data Availability Statement: Not applicable.

Conflicts of Interest: The authors declare no conflict of interest.

\section{References}

1. Cameira, M.D.R.; Mota, M. Nitrogen Related Diffuse Pollution from Horticulture Production-Mitigation Practices and Assessment Strategies. Horticulturae 2017, 3, 25. [CrossRef]

2. Kuntosch, A.; König, B.; Bokelmann, W.; Doernberg, A.; Siebert, R.; Schwerdtner, W.; Busse, M. Identifying System-Related Barriers for the Development and Implementation of Eco-Innovation in the German Horticultural Sector. Horticulturae 2020, 6, 33. [CrossRef]

3. Valenzuela, H. Agroecology: A Global Paradigm to Challenge Mainstream Industrial Agriculture. Horticulturae 2016, 2, 2. [CrossRef]

4. Lehtonen, H.; Palosuo, T.; Korhonen, P.; Liu, X. Higher Crop Yield Levels in the North Savo Region-Means and Challenges Indicated by Farmers and Their Close Stakeholders. Agriculture 2018, 8, 93. [CrossRef]

5. Mantino, F.; Forcina, B. Market, Policies and Local Governance as Drivers of Environmental Public Benefits: The Case of the Localised Processed Tomato in Northern Italy. Agriculture 2018, 8, 34. [CrossRef]

6. Salvia, R.; Simone, R.; Salvati, L.; Quaranta, G. Soil Conservation Practices and Stakeholder's Participation in Research ProjectsEmpirical Evidence from Southern Italy. Agriculture 2018, 8, 85. [CrossRef]

7. Chen, H.; Zhong, T.; Lee, J. Capacity Reduction Pressure, Financing Constraints, and Enterprise Sustainable Innovation Investment: Evidence from Chinese Manufacturing Companies. Sustainability 2020, 12, 10472. [CrossRef]

8. Empidi, A.V.A.; Emang, D. Understanding Public Intentions to Participate in Protection Initiatives for Forested Watershed Areas Using the Theory of Planned Behavior: A Case Study of Cameron Highlands in Pahang, Malaysia. Sustainability 2021, 13, 4399. [CrossRef]

9. Geerts, M.; Dooms, M.; Stas, L. Determinants of Sustainability Reporting in the Present Institutional Context: The Case of Port Managing Bodies. Sustainability 2021, 13, 3148. [CrossRef]

10. Ghimire, A.; Lin, F.; Zhuang, P. The Impacts of Agricultural Trade on Economic Growth and Environmental Pollution: Evidence from Bangladesh Using ARDL in the Presence of Structural Breaks. Sustainability 2021, 13, 8336. [CrossRef]

11. Latini, A.; Giagnacovo, G.; Campiotti, C.A.; Bibbiani, C.; Mariani, S. A Narrative Review of the Facts and Perspectives on Agricultural Fertilization in Europe, with a Focus on Italy. Horticulturae 2021, 7, 158. [CrossRef]

12. Li, Z.; Wu, Y.; Xing, D.; Zhang, K.; Xie, J.; Yu, R.; Chen, T.; Duan, R. Effects of Foliage Spraying with Sodium Bisulfite on the Photosynthesis of Orychophragmus violaceus. Horticulturae 2021, 7, 137. [CrossRef]

13. Rudinskaya, T.; Náglová, Z. Analysis of Consumption of Nitrogen Fertilisers and Environmental Efficiency in Crop Production of EU Countries. Sustainability 2021, 13, 8720. [CrossRef]

14. Ryszko, A. Proactive Environmental Strategy, Technological Eco-Innovation and Firm Performance-Case of Poland. Sustainability 2016, 8, 156. [CrossRef]

15. Tjahjadi, B.; Soewarno, N.; Hariyati, H.; Nafidah, L.N.; Kustiningsih, N.; Nadyaningrum, V. The Role of Green Innovation between Green Market Orientation and Business Performance: Its Implication for Open Innovation. J. Open Innov. Technol. Mark. Complex. 2020, 6, 173. [CrossRef]

16. Zhang, Y.; Sun, J.; Yang, Z.; Li, S. Organizational Learning and Green Innovation: Does Environmental Proactivity Matter? Sustainability 2018, 10, 3737. [CrossRef]

17. Ge, B.; Yang, Y.; Jiang, D.; Gao, Y.; Du, X.; Zhou, T. An Empirical Study on Green Innovation Strategy and Sustainable Competitive Advantages: Path and Boundary. Sustainability 2018, 10, 3631. [CrossRef]

18. Song, W.; Yu, H. Green Innovation Strategy and Green Innovation: The Roles of Green Creativity and Green Organizational Identity. Corp. Soc. Responsib. Environ. Manag. 2018, 25, 135-150. [CrossRef]

19. Chang, C.-H. Green Open Innovation Activities and Green Co-Innovation Performance in Taiwan's Manufacturing Sector. Int. J. Environ. Res. Public Health 2020, 17, 6677. [CrossRef] [PubMed]

20. Fang, W.; Wu, T.-H.; Chang, T.-W.; Hung, C.-Z. What Could Entrepreneurial Vision Do for Sustainable Development? Explore the Cross-Level Impact of Organizational Members' Green Shared Vision on Green Creativity. Sustainability 2021, 13, 5364. [CrossRef]

21. Huang, S.Y.B.; Lee, S.-C.; Lee, Y.-S. Why Can Green Social Responsibility Drive Agricultural Technology Manufacturing Company to Do Good Things? A Novel Adoption Model of Environmental Strategy. Agronomy 2021, 11, 1673. [CrossRef]

22. Meidute-Kavaliauskiene, I.; Çiğdem, Ş.; Vasilis Vasiliauskas, A.; Yıldız, B. Green Innovation in Environmental Complexity: The Implication of Open Innovation. J. Open Innov. Technol. Mark. Complex. 2021, 7, 107. [CrossRef]

23. Skordoulis, M.; Ntanos, S.; Kyriakopoulos, G.L.; Arabatzis, G.; Galatsidas, S.; Chalikias, M. Environmental Innovation, Open Innovation Dynamics and Competitive Advantage of Medium and Large-Sized Firms. J. Open Innov. Technol. Mark. Complex. 2020, 6, 195. [CrossRef] 
24. Walder, P.; Sinabell, F.; Unterlass, F.; Niedermayr, A.; Fulgeanu, D.; Kapfer, M.; Melcher, M.; Kantelhardt, J. Exploring the Relationship between Farmers' Innovativeness and Their Values and Aims. Sustainability 2019, 11, 5571. [CrossRef]

25. Montes de Oca Munguia, O.; Pannell, D.J.; Llewellyn, R. Understanding the Adoption of Innovations in Agriculture: A Review of Selected Conceptual Models. Agronomy 2021, 11, 139. [CrossRef]

26. Goodhue, D.L.; Thompson, R.L. Task-Technology Fit and Individual Performance. MIS Q. 1995, 19, 213-236. [CrossRef]

27. Ajzen, I. From Intentions to Actions: A Theory of Planned Behavior; Series in Social Psychology; Kuhl, J., Beckmann, J., Eds.; Springer: Berlin, Germany, 1985; pp. 11-39.

28. Davis, F.D.; Bagozzi, R.P.; Warshaw, P.R. User acceptance of computer technology: A comparison of two theoretical models. Manag. Sci. 1989, 35, 982-1003. [CrossRef]

29. Bandura, A. Social Foundations of Thought and Action: A Social Cognitive Theory; Prentice-Hall: Englewood Cliffs, NJ, USA, 1986.

30. Freire, C.; Gonçalves, J. The Relationship between Responsible Leadership and Organizational Citizenship Behavior in the Hospitality Industry. Sustainability 2021, 13, 4705. [CrossRef]

31. Voegtlin, C.; Patzer, M.; Scherer, A.G. Responsible Leadership in Global Business: A New Approach to Leadership and Its Multi-Level Outcomes. J. Bus. Ethics 2011, 105, 1-16. [CrossRef]

32. Daily, B.F.; Bishop, J.W.; Govindarajulu, N. A Conceptual Model for Organizational Citizenship Behavior Directed Toward the Environment. Bus. Soc. 2009, 48, 243-256. [CrossRef]

33. Ghosh, P.R.; Fawcett, D.; Perera, D.; Sharma, S.B.; Poinern, G.E.J. Horticultural Loss Generated by Wholesalers: A Case Study of the Canning Vale Fruit and Vegetable Markets in Western Australia. Horticulturae 2017, 3, 34. [CrossRef]

34. Steffens, J.; Brüssow, K.; Grote, U. A Strategic Approach to Value Chain Upgrading-Adopting Innovations and Their Impacts on Farm Households in Tanzania. Horticulturae 2020, 6, 32. [CrossRef]

35. Bollen, K.A.; Curran, P.J. Latent Curve Models: A Structural Equation Perspective; Wiley: Hoboken, NJ, USA, 2006.

36. Lawrence, P.R.; Pirson, M. Economistic and Humanistic Narratives of Leadership in the Age of Globality: Toward a Renewed Darwinian Theory of Leadership. J. Bus. Ethics 2014, 128, 383-394. [CrossRef]

37. Wang, Y.; Shen, T.; Chen, Y.; Carmeli, A. CEO environmentally responsible leadership and firm environmental innovation: A socio-psychological perspective. J. Bus. Res. 2021, 126, 327-340. [CrossRef]

38. Haque, A.; Fernando, M.; Caputi, P. The Relationship Between Responsible Leadership and Organisational Commitment and the Mediating Effect of Employee Turnover Intentions: An Empirical Study with Australian Employees. J. Bus. Ethics 2017, 156, 759-774. [CrossRef]

39. Haque, A.; Fernando, M.; Caputi, P. Responsible leadership, affective commitment and intention to quit: An individual level analysis. Leadersh. Organ. Dev. J. 2019, 40, 45-64. [CrossRef]

40. Bono, J.E.; Judge, T.A. Self-concordance at work: Toward understanding the motivational effects of transformational leaders. Acad. Manag. J. 2003, 46, 554-571.

41. Yang, X. The Impact of Responsible Leadership on Employee Green Behavior: Mediating Effect of Moral Reflectiveness and Moderating Effect of Empathy. IOP Conf. Ser. Mater. Sci. Eng. 2019, 677, 052054. [CrossRef]

42. Cai, W.; Yang, C.; Bossink, B.A.G.; Fu, J. Linking Leaders' Voluntary Workplace Green Behavior and Team Green Innovation: The Mediation Role of Team Green Efficacy. Sustainability 2020, 12, 3404. [CrossRef]

43. Huang, S.; Fei, Y.-M.; Lee, Y.-S. Predicting Job Burnout and Its Antecedents: Evidence from Financial Information Technology Firms. Sustainability 2021, 13, 4680. [CrossRef]

44. Lee, C.-J.; Huang, S.Y. Can ethical leadership hinder sales performance? A limited resource perspective of job embeddedness. Chin. Manag. Stud. 2019, 13, 985-1002. [CrossRef]

45. Lee, C.-J.; Huang, S.Y. Double-edged effects of ethical leadership in the development of Greater China salespeople's emotional exhaustion and long-term customer relationships. Chin. Manag. Stud. 2020, 14, 29-49. [CrossRef]

46. Liu, S.-Y.; Yen, C.-Y.; Tsai, K.-N.; Lo, W.-S. A Conceptual Framework for Agri-Food Tourism as an Eco-Innovation Strategy in Small Farms. Sustainability 2017, 9, 1683. [CrossRef]

47. Malhotra, N.K.; Kim, S.S.; Patil, A. Common Method Variance in IS Research: A Comparison of Alternative Approaches and a Reanalysis of Past Research. Manag. Sci. 2006, 52, 1865-1883. [CrossRef]

48. Podsakoff, P.M.; MacKenzie, S.B.; Lee, J.; Podsakoff, N.P. Common method biases in behavioral research: A critical review of the literature and recommended remedies. J. Appl. Psychol. 2003, 88, 879-903. [CrossRef]

49. Boiral, O.; Paillé, P. Organizational citizenship behavior for the environment: Measurement and validation. J. Bus. Ethics. 2012, 109, 431-445. [CrossRef]

50. Fornell, C.; Lacker, D.F. Evaluating structural equation models with unobservable variables and measurement error. J. Mark. Res. 1981, 18, 39-50. [CrossRef]

51. Hazarika, N. R\&D Intensity and Its Curvilinear Relationship with Firm Profitability: Perspective from the Alternative Energy Sector. Sustainability 2021, 13, 5060. [CrossRef]

52. Khan, A.; Chen, L.-R.; Hung, C.-Y. The Role of Corporate Social Responsibility in Supporting Second-Order Social Capital and Sustainable Innovation Ambidexterity. Sustainability 2021, 13, 6994. [CrossRef]

53. Qamruzzaman, M.; Tayachi, T.; Mehta, A.M.; Ali, M. Do International Capital Flows, Institutional Quality Matter for Innovation Output: The Mediating Role of Economic Policy Uncertainty. J. Open Innov. Technol. Mark. Complex. 2021, 7, 141. [CrossRef] 
54. Iqbal, Q.; Ahmad, N.; Li, Y. Sustainable Leadership in Frontier Asia Region: Managerial Discretion and Environmental Innovation. Sustainability 2021, 13, 5002. [CrossRef]

55. Jia, J.; Liu, H.; Chin, T.; Hu, D. The Continuous Mediating Effects of GHRM on Employees' Green Passion via Transformational Leadership and Green Creativity. Sustainability 2018, 10, 3237. [CrossRef]

56. Wooldridge, B.; Schmid, T.; Floyd, S.W. The Middle Management Perspective on Strategy Process: Contributions, Synthesis, and Future Research. J. Manag. 2008, 34, 1190-1221. [CrossRef]

57. Calder, B.J.; Phillips, L.W.; Tybout, A.M. Designing Research for Application. J. Consum. Res. 1981, 8, 197-207. [CrossRef] 